\title{
O SUS como Desafio para a Formação em Psicologia
}

The Brazilian National Health System as a Challenge to the Education In Psychology

El SUS como Desafío para la Formación en Psicología

Ianni Regia Scarcelli Universidade de São Paulo

Virgínia Junqueira Universidade

Federal de São Paulo

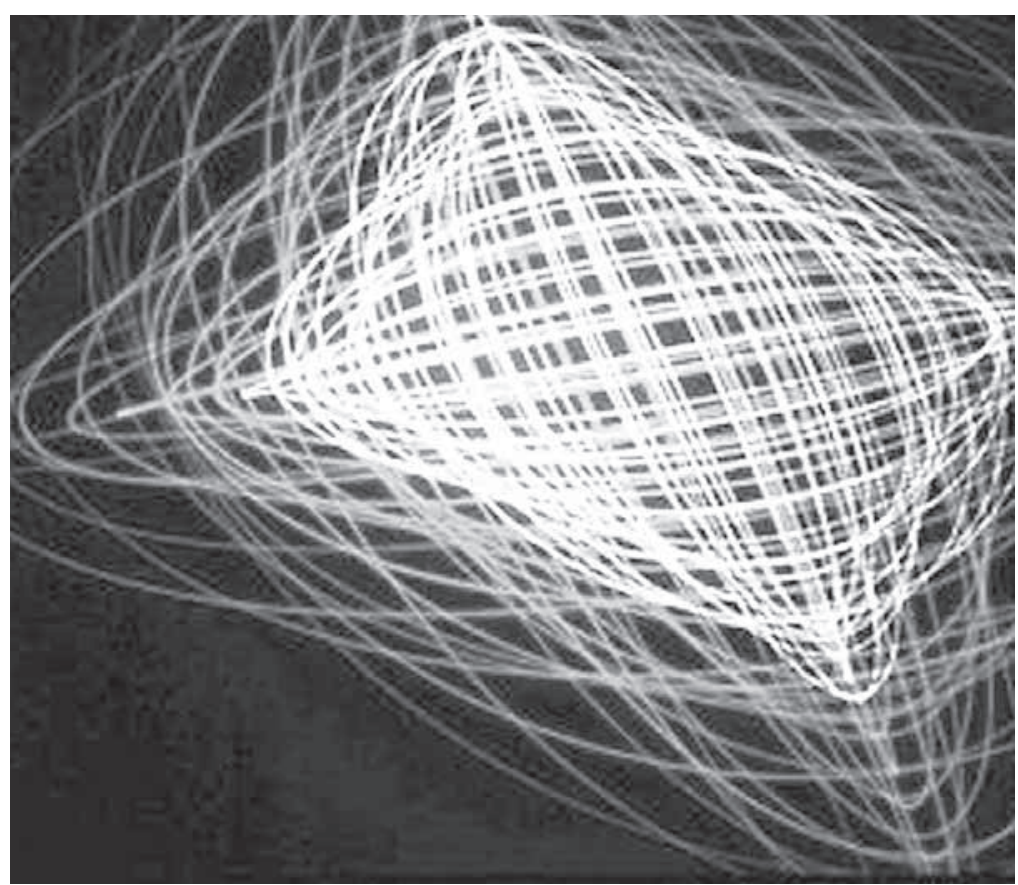


Resumo: O objetivo deste artigo é refletir sobre as possibilidades de aproximação da Psicologia ao Sistema Único de Saúde (SUS) e ao campo da saúde coletiva, considerando a formação um aspecto intrinsecamente relacionado à produção de conhecimento e ao fundamento da prática profissional. A partir de revisão bibliográfica de trabalhos recentes que tratam de aspectos político-jurídicos do SUS, da análise de documentos governamentais e da experiência das autoras com o trabalho de gestão e atenção no sistema e serviços de saúde, são discutidas questões políticas, organizativas e administrativas que incidem sobre a construção do sistema nacional público de saúde no Brasil como aspectos fundamentais de um novo cenário de atuação em Psicologia. Indaga-se, nesse contexto, em que medida é possível desenvolver um trabalho que não se restrinja a ser complementar a saberes e fazeres já estabelecidos. Tomando o tema da formação como aspecto importante na construção do SUS, o debate se encaminha no sentido de problematizar o comparecimento da Psicologia em espaços onde transitam diferentes atores e saberes, onde se cultiva o ato de interrogar e de ressignificar práticas e políticas públicas. Essa seria, em tese, não só uma forma de contribuição dos saberes psi mas também de ressignificação do próprio campo.

Palavras-chave: Sistema Único de Saúde. Psicologia. Saúde pública. Formação do psicólogo.

Abstract: The goal of this article is to reflect on the possibilities of bringing psychology near to the Brazilian National Health System (SUS) and to the collective health field, considering training as an aspect intrinsically related to the knowledge production and basis for the professional practice. Having as starting points a bibliographic review of recent works dealing with the political and legal aspects of SUS, an analysis of the government documents and the authors' work experience in the health system and services management, there is a discussion on the subjects related to the political, organizational and administrative issues that focus the national public health system construction in Brazil as fundamental aspects of a new scenario in Psychology. Therefore, in this context, questions were asked about whether it would be possible to develop a work that is not restricted to complement the knowledge and the practices already established. Taking the training issue as inseparable from the knowledge production and as an important aspect in the construction of SUS, the discussion focus the introduction of Psychology in different knowledge fields and different actors, stimulating questions and changing practices and public policies. This would theorethically contribute for Psychology knowledge and also would resignify the psy field.

Keywords: Brazilian National Health System. Psychology. Publice health. Psychologist education.

Resumen: El objetivo de este artículo es reflexionar sobre las posibilidades de aproximación de la Psicología al Sistema Único de Salud (SUS) y al campo de la salud colectiva, considerando la formación un aspecto intrínsecamente relacionado a la producción de conocimiento y al fundamento de la práctica profesional. Desde una revisión bibliográfica de trabajos recientes que tratan de aspectos políticos y jurídicos del SUS, del análisis de documentos gubernamentales y de la experiencia de las autoras con la gestión del trabajo y la atención en el sistema y servicios de salud, son discutidos asuntos políticos, organizativos y administrativos que inciden sobre la construcción del sistema nacional público de salud en Brasil como aspectos fundamentales de un nuevo escenario de actuación en Psicología. Se pregunta en ese contexto, en qué medida es posible desarrollar un trabajo que no se limita a ser complementar a los conocimientos y prácticas ya establecidos. Considerando el tema de la formación como aspecto importante en la construcción del SUS, la discusión es direccionada para problematizar la presencia de la Psicología en espacios donde transitan diferentes actores y conocimientos, donde se cultiva el acto de interrogar y de dar un nuevo significado a prácticas y políticas públicas. Ésa sería, en tesis, no sólo una manera de contribución de los conocimientos psi, pero también de dar un nuevo significado al propio campo.

Palabras clave: Sistema Único de Salud. Psicología. Salud publica. Formación del psicólogo.

O tema proposto para esta discussão implica, entre outras, uma reflexão sobre a possibilidade de aproximação da Psicologia ao Sistema Único de Saúde (SUS) e ao campo da saúde coletiva, considerando aspectos que envolvem formação, produção de conhecimento e prática profissional. Parte-se do pressuposto que formação e investigação não devem ser tomadas separadamente, pois estão intrinsecamente relacionadas e trazem os fundamentos da prática profissional que, por sua vez, redimensionam e possibilitam a ressignificação desses seus próprios fundamentos.

Historicamente, formação é um tema que ocupa lugar de destaque nos debates concernentes à definição de políticas 
públicas e à reestruturação dos serviços de saúde que diz respeito, entre outros, ao ensino de graduação, pós-graduação e educação permanente no processo de trabalho. As propostas de reorganização do sistema de atenção se encontram acompanhadas de discussões sistemáticas no sentido de se definir diretrizes para a formulação de uma política de recursos humanos em âmbito nacional.

Considerando tais aspectos e os desafios que o SUS nos apresenta, para subsidiar a reflexão aqui proposta, foram feitas revisão bibliográfica de trabalhos recentes que tratam de aspectos político-jurídicos do SUS e análise de documentos governamentais, e também incluídas as experiências das autoras no trabalho de gestão e de atenção no sistema e serviços de saúde e na docência do ensino universitário. São discutidas questões políticas, organizativas e administrativas que incidem na construção do sistema nacional público de saúde no Brasil, levando-se em conta o fato de que, para refletir sobre os aspectos relacionados à formação nesse movimento de aproximação do campo psi à realidade complexa que se apresenta, interessa contextualizar projetos e proposições políticas que vêm abordando temas relevantes para a produção teórica no campo da Psicologia.

Essa tarefa exige que nos detenhamos, em um primeiro momento, sobre o que vem a ser o SUS no Brasil, tematizando as injunções políticas que se colocaram na construção desse sistema nacional público, os seus conceitos fundantes e os riscos das possíveis capturas que se expressam nos âmbitos macro e micropolíticos. Em um segundo momento, problematizamos os desafios que o SUS traz para o campo da Psicologia, particularmente no que se refere à formação relativa ao cenário que se apresenta.

\section{SUS - injunções políticas, conceitos e dilemas na sua construção}

Desde a década de 90, multiplicaram-se a cada ano os quantitativos de produção de atos e procedimentos do SUS, demonstrando os inegáveis avanços obtidos no que concerne à cobertura da população brasileira, de acordo com Santos (2008). Em contraste, como reconhecido por esse autor e por vários outros estudos, existem impedimentos de diversas ordens, com destaque para o subfinanciamento e a precarização da gestão de pessoal (Santos, 2007; Carvalho, 2002; ABRASCO, CEBES, ABRES, Rede Unida, \& AMPASA, 2005).

Como decorrência, ressalta-se também a baixa qualidade referida por usuários e trabalhadores dos serviços. Na atenção básica, considerada unanimemente o elemento estruturante do sistema, há diversas explicações para isso: insuficiência nos quadros de pessoal, inexistência de equipes multiprofissionais, desvinculação entre a atenção básica e os demais serviços, como unidades de pronto-atendimento, ambulatórios de especialidade e a assistência de pronto-socorro e hospitalar, que também não se articulam entre si e que são operados oficiosamente de forma privatista. Assim é que não se conhecem e não se controlam publicamente os critérios para agendamento de exames de alta complexidade, consultas de especialidades, cirurgias eletivas e tratamentos como radio e quimioterapia, para os quais o tempo de espera varia de meses a anos. Por outro lado, constata-se o predomínio da ampliação das equipes dos Programas de Saúde da Família (PSF) e de agentes comunitários de saúde (PACS), com direcionamento focado na população pobre. A priorização do nível básico de atenção 
Segundo Almeida, a descentralização setorial no Brasil se integra a um processo no qual se transita de "uma forma extrema de federalismo centralizado para alguma modalidade de federalismo cooperativo, ainda não completamente definido" (2003, p. 210). se faz presente apenas no discurso. Os profissionais das unidades básicas de saúde não recebem incentivos salariais, ao contrário do que recomenda o Pacto pela Saúde, subscrito pelos representantes dos três níveis de gestão do SUS e aprovado pelo Conselho Nacional de Saúde em 2006 (Brasil, 2006).

Sinalizando o predomínio de interesses dos grandes prestadores e da indústria de equipamentos, recursos consideravelmente mais elevados remuneram os procedimentos de alta complexidade, quando comparados àqueles destinados ao Piso da Atenção Básica, no qual se incluem todos os procedimentos básicos, com exceção do PSF. Este último é um programa relativamente caro, cuja força de trabalho é majoritariamente terceirizada e que tem constituído instrumento para a transferência de responsabilidades sanitárias e de recursos financeiros do poder público para entidades privadas. Intimamente relacionada à precarização das relações de trabalho nos três níveis de gestão e, mais particularmente, às administrações estaduais e municipais, está a adoção oficial de novas e privatizantes formas de gestão, em um quadro de não utilização, pelo Estado, de instrumentos públicos de controle e do não exercício da autoridade de regulação (Nogueira, 2006). Na mesma linha de descontrole por parte dos governos, há a desregulamentação da produção de medicamentos, de equipamentos médico-hospitalares e imunobiológicos e as concessões frente à pressão dos interesses corporativos interna e externamente ao sistema - espaços legislativos, conselhos profissionais e associações científicas.

A instabilidade de sustentação orçamentáriofinanceira evidencia-se pela procrastinação indefinida da regulamentação da Emenda
Constitucional no 29, que permanece inconclusa, permitindo que o gestor federal escape a um comprometimento estável de recursos e também que os governantes dos níveis estaduais e municipais destinem recursos da saúde para outros fins.

O federalismo da organização política brasileira é um desafio para a construção de um sistema que tem como diretriz a descentralização via municipalização, e como um de seus enunciados o comando único em cada esfera do sistema. Segundo Almeida, a descentralização setorial no Brasil se integra a um processo no qual se transita de "uma forma extrema de federalismo centralizado para alguma modalidade de federalismo cooperativo, ainda não completamente definido" (2003, p. 210).

O Pacto de Gestão, componente do Pacto pela Saúde, assinado pelas três esferas de governo no início de 2006, assenta-se no reconhecimento que a descentralização e a regionalização constituem questões eminentemente políticas, não devendo ser tratadas por meio de portarias burocráticas, como foi o caso das que editaram as Normas Operacionais, notadamente a Norma Operacional de Assistência à Saúde - NOAS 2001 e 2002 (Brasil, 2002, 2006).

Todos esses impasses apontam a presença de distintas formas de se compreender esse sistema de saúde, seus princípios e, em consequência, as diversas estratégias para executar políticas públicas e implementar práticas. As diferentes formas de compreensão e implementação do SUS são fundamentadas em determinadas concepções de Estado, de sociedade, de sujeito, de saúde, de educação. Em outros termos, dizem respeito ao conjunto de interesses que mobilizam os atores que se agregam em torno desse 
projeto: governantes, partidos políticos, empresários, movimentos sociais, estudantes, intelectuais, entidades filantrópicas, conselhos profissionais, associações de classes, sindicatos, etc.

Esses interesses variam de posições políticas comprometidas com os direitos da maioria da população brasileira àqueles vinculados à iniciativa privada. Não obstante, o SUS é conquista de um movimento social que envolveu diversos setores da sociedade, entre os quais se destacaram intelectuais do meio universitário, lideranças políticas, estudantis e militantes do movimento popular. Foi no interior da luta contra a ditadura militar que se constituiu o movimento pela Reforma Sanitária Brasileira, enfrentando-se conflitos advindos de interesses distintos - e mesmo antagônicos - que já tornavam visíveis algumas das dificuldades para a sustentação desse projeto. Ao mesmo tempo, o aparelho repressivo do Estado colocava vários impedimentos à ampliação da base popular do movimento (Campos, 1988). De acordo com Paim, a redemocratização do Brasil e a conquista de um arcabouço legal que sustenta o sistema nacional público de saúde no País não foram suficientes para que o movimento da Reforma Sanitária Brasileira avançasse para além de "mera reforma parcial" (Paim, 2008, p.634). Cabe assinalar que há autores, como Cohn, que enfatizam, em contraponto, as conquistas e os avanços obtidos na trajetória da construção do SUS, considerando ter havido derrota do modelo neoliberal (Cohn, 2008).

Desde seu momento inicial, a reforma sanitária enfrentou oposição por parte do empresariado da assistência médica e da indústria farmacêutica, que identificavam a construção de um sistema público de saúde como uma ameaça à exploração mercantil na área da saúde. Contudo, o discurso de lideranças políticas ligadas a esses setores confunde-se aparentemente com aquele que assume a defesa e o fortalecimento do SUS. Na verdade, o setor privado apoia a segmentação da assistência: de um lado, os que pagam planos de saúde, e, de outro, os que devem se contentar com um sistema voltado para os pobres. Em decorrência, o SUS não é um projeto suprapartidário, mas uma arena de disputa de projetos. Campos identifica dois projetos sanitários polares no cenário de disputa: o que corresponde aos sistemas nacionais de saúde, que se contrapõe à alternativa liberal-privatista (Campos, 2007). O autor ressalva que, na realidade, ocorre mescla de combinações de elementos de ambos os projetos.

As disputas são também evidentes no âmbito da reforma psiquiátrica brasileira, onde o maior acirramento se encontra entre militantes do movimento antimanicomial e empresários da assistência hospitalar. Quando nos perguntamos sobre o porquê de tantas dificuldades relacionadas ao desmonte dos hospitais psiquiátricos no Brasil e sobre os motivos de ocorrer a redução do número de leitos pelos hospitais privados, mantendo-se estes, contudo, subsidiados por verbas públicas para implantar serviços substitutivos (hospital-dia, centro de atenção psicossocial, serviço residencial terapêutico, etc.), podemos perceber que o segmento empresarial continua sendo beneficiado no contexto dessa luta política.

A decisão de iniciar o texto pela discussão precedente - conflitos de interesses que envolvem a construção do SUS - sustenta-se no entendimento de que, ao se objetivar a aproximação das contribuições da Psicologia como campo de conhecimento, como atuação profissional e como formação a 
essa realidade tão complexa, é necessário que projetos e proposições políticas sejam contextualizados, e que não sejam, assim, tomados como verdades inquestionáveis que representariam modelos a serem apenas aperfeiçoados.

Considerando tal perspectiva, mais adiante focaremos os princípios e as diretrizes do SUS e dois projetos que têm sido objeto de discursos que muitas vezes tendem a um posicionamento triunfalista: o Programa de Saúde da Família - PSF e os Centros de Atenção Psicossocial (CAPS), ambos objetos de indução financeira pelo Ministério da Saúde junto aos Municípios.

\section{Conceitos fundantes do SUS}

No ano 1986, encerrado o período da ditadura militar, ocorreu um dos grandes marcos do processo de redemocratização no Brasil: a realização da VIII Conferência Nacional de Saúde. As resoluções dessa conferência foram defendidas pelos militantes da reforma sanitária na Assembléia Nacional Constituinte, entre 1987 e 1988. Vitórias parciais foram obtidas no processo da Constituinte, consolidadas no capítulo Saúde da Constituição Federal (Brasil, 1988) e, posteriormente, instituídas na Lei do SUS - Lei no 8.080, de 1990 (Brasil, 1990a). O capítulo constitucional sobre saúde dispõe que as redes de serviços até então administradas pelas diferentes esferas do governo (federal, estadual e municipal) devem dar lugar a um sistema único e descentralizado operado mediante a municipalização da rede pública.

São princípios doutrinários do SUS:

Universalidade: todas as pessoas, independentemente de diferença de classe, cor, raça, crença, etc., têm o direito de acesso ao sistema de saúde.

Igualdade: todo cidadão é igual perante o sistema e deve ser atendido de acordo com suas necessidades, que são diferenciadas conforme sua posição social.

Integralidade:_as ações de saúde devem ser voltadas ao mesmo tempo para a proteção, a promoção e a recuperação, e o indivíduo deve ser concebido como ser humano integral nas suas necessidades físicas, psíquicas e sociais.

Os princípios organizativos fundamentais do SUS são:

Descentralização por meio da municipalização.

Regionalização com hierarquização da atenção.

- Controle social, que se dá pela participação popular no controle do sistema, exercido por conselhos de caráter deliberativo, que devem ser criados em todos os níveis de gestão. Conforme a Lei Federal no 8.142, de 1990 (Brasil, 1990b), o Conselho de Saúde é órgão colegiado composto por representantes do governo, prestadores de serviço, profissionais de saúde e usuários; tem caráter permanente e deliberativo e atua na formulação de estratégias e no controle da execução política de saúde na instância correspondente (federal, estadual, municipal e local).

Em cada um desses níveis, os Conselhos, que são compostos por $50 \%$ de representantes dos usuários, 25\% de representantes de trabalhadores, os $25 \%$ restantes divididos entre representantes do governo e prestadores 
de serviços, devem aprovar o plano de saúde elaborado a partir da análise de condição de vida e da situação de saúde da população e explicitando as ações a serem desenvolvidas, seja no setor saúde, seja com os demais setores do governo (Brasil, 2003).

A intersetorialidade é outro princípio importante do SUS que merece ser destacado. Considerar a intersetorialidade implica conceber que saúde não se restringe à assistência médica. As respostas dadas pelo sistema de saúde, de acordo com o princípio da integralidade, levam em conta que a ação deve ser de natureza interdisciplinar e intersetorial, envolvendo as dimensões do trabalho, habitação, lazer, educação, cultura, etc. De acordo com Mendes (1996), a interdisciplinaridade tem, na construção do saber, significação semelhante à intersetorialidade no campo do fazer.

Esses são princípios caros aos SUS, entre outros aspectos, ao fazerem frente às fragmentações do conhecimento humano com suas antinomias, políticas, ações no território, no modo de viver dos sujeitos (Scarcelli \& Alencar, 2008).

Tais questões nos conduzem ao aprofundamento e ao debate sobre concepções de saúde, promoção, prevenção e reabilitação, e são temas que preocupam estudiosos e disciplinas que se agregam em torno da saúde coletiva. Elas nos levam a considerar, portanto, que saúde não é apenas estado de normalidade relacionado a bem-estar biopsicossocial; é também uma sucessão de compromissos com a realidade do ambiente material, com a realidade afetiva, relacional e familiar e com a realidade social (Dejours, 1986).

Ressalta-se que, embora tais concepções estejam em constante debate e sejam orientadoras de proposições políticas abrangentes e de caráter interdisciplinar, é possível constatar que temas relacionados ao sujeito e à subjetividade têm sido considerados de caráter mais complementar e menos constitutivo da integralidade que se procura construir em tais concepções. Cecilio (2001), observa como é importante considerar a recursividade das esferas das micropolíticas e das macropolíticas para repensar a organização do processo de trabalho, a gestão e a construção de saberes e práticas. Merhy (2002) assinala que a natureza do trabalho em saúde faz com que ele se realize no encontro entre os trabalhadores de saúde, sejam indivíduos ou coletivos, e os que demandam atenção. Nesse território impreciso se trava a disputa entre a realização da saúde como bem de mercado subordinado à acumulação do capital e um projeto de saúde concebido e operado como bem público e patrimônio coletivo e individual de uma sociedade.

No campo da saúde coletiva, é a saúde mental que se apresenta como a área que mais recupera a questão da subjetividade - expressa também pela crítica à razão iluminista e pela inclusão da desrazão na proposta de novo paradigma - como essencial para a construção de uma concepção de saúde mais abrangente. Não é raro, porém, nos depararmos com uma dicotomização entre essa área e a da saúde geral: ora por enfatizar e privilegiar a questão da subjetividade, beirando a psicologização, afastando-se do campo da saúde coletiva, ora por afastar-se desse campo por ser considerada excessivamente psi, apesar de trazer elementos fundamentais que, em geral, são subestimados por aqueles que atuam na área. Nesse sentido, a Psicologia esteve limitada quase que exclusivamente a 
explicar processos psicológicos em situações que possam esclarecer as dúvidas sobre questões enigmáticas (Scarcelli, 2002).

Contudo, atualmente a complexidade que envolve a concepção de saúde e que se coloca como desafio na constituição do SUS tem sido temática relevante no âmbito da Psicologia. Considerando que os psicólogos estão presentes na produção de conhecimento, na proposição política e na implementação de práticas no campo da saúde, apresentam-se como importantes as questões que dizem respeito a quais possibilidades as contribuições dos saberes psi podem trazer a esse campo e a como esses mesmos saberes podem ser ampliados com a participação nesse debate.

As pedras no meio do caminho

Abordamos até o momento temas relacionados à gestação do SUS, a seus princípios e à problematização da concepção de saúde. Devemos nos lembrar, no entanto, que a implementação desse sistema exige destinação de recursos financeiros, e é principalmente nesse aspecto que os conflitos gerados pelos interesses em jogo se manifestam.

O ponto de partida da regulamentação dos princípios constitucionais se deu pela Lei Federal no 8.080, de setembro de 1990, em cujo conteúdo estão inscritas algumas derrotas do Movimento da Reforma Sanitária: reconhecimento do direito à exploração da assistência à saúde pela iniciativa privada e os vetos aos artigos que tratavam do financiamento e do controle público pelo governo de Fernando Collor de Mello que, fundamentado na visão neoliberal de crise econômica, apostava em políticas de redução do Estado considerado ineficiente, inoperante, corrupto e composto por um funcionalismo público usurpador.

Em consequência desses vetos, em condições adversas para construção do SUS, depois de muita negociação, a Lei oㅡ 8.142 foi editada em dezembro desse mesmo ano com os artigos referentes à participação popular e ao financiamento, cujo conteúdo foi bastante rebaixado. Não se obteve a vinculação do orçamento da saúde a um percentual fixo de recursos, o que provocou a incerteza sobre as fontes de financiamento que variavam a cada ano.

Nesse quadro político de orientação neoliberal, as medidas necessárias para a implantação do SUS ficaram em suspenso até 1991, quando foi editada a primeira Norma Operacional Básica (NOB), que regulamentou uma forma de financiamento que só fazia perpetuar a lógica da produtividade: os Municípios começaram a receber pagamento pela realização de procedimentos, da mesma forma que os prestadores privados contratados pelo SUS. Os gestores municipais eram tratados, portanto, como se fossem meros prestadores de serviços de saúde, a exemplo de laboratórios, clínicas e hospitais privados (Brasil, 1991).

Depois da renúncia do presidente Collor de Melo, em 1993, outra NOB foi editada como resultado de mobilização social concretizada na realização da IX Conferência Nacional de Saúde, em 1992, cujo tema foi a municipalização. Essa norma operacional instituía a modalidade semiplena de gestão, ou seja, a possibilidade de os Municípios serem gestores dos serviços da atenção básica (Brasil, 1993). Com a NOB no 93, pela primeira vez os Municípios puderam exercer esse papel. 
Foi no ano 1994 que os secretários municipais de saúde, militantes do Movimento de Reforma Sanitária, se dispuseram a assumir a gestão semiplena em seus Municípios, o que representava um desafio, pois o quadro era ainda de incerteza quanto aos valores dos recursos financeiros a serem recebidos e à possibilidade de interrupção dos repasses dos governos estadual e federal. Apenas 24 Municípios assumiram essa forma de gestão.

A partir de 1994, durante o governo de Fernando Henrique Cardoso, poucos foram os estímulos por parte do gestor federal para que o SUS avançasse nesse sentido. Em 1996, apenas 144 Municípios em todo o Brasil eram gestores semiplenos do sistema de saúde. Apesar dos entraves, esse momento foi marcado pelo avanço da participação popular nos conselhos de saúde e pela ampliação e diversificação de serviços oferecidos à população nos Municípios que aderiram à gestão semiplena (Heimann, Cortizo, Castro, Kayano, Rocha, Nascimento, Boaretto, Pessoto, \& Junqueira, 2000).

Um novo momento de retrocesso se instalou no País, a partir da reforma de Estado implementada pelo extinto Ministério da Administração Federal e de Reforma de Estado (MARE) no governo de Fernando Henrique. Denominada contra-reforma por muitos autores (Noronha \& Soares, 2001), baseou-se, entre outras premissas, na culpabilização do funcionalismo público na gênese da crise do Estado. Como consequência desse diagnóstico, a alternativa apontada foi a transferência de funções antes consideradas obrigações estatais próprias do serviço público para a iniciativa privada ou para o chamado setor "público não estatal".

As consequências dessa contra-reforma atingiram diretamente o processo de construção do SUS, sob várias formas. Paim e Teixeira (2007), apontam como as reformas de cunho gerencialista provocaram fragmentação dos processos de gestão principalmente nos níveis estaduais e municipais do sistema. Também a edição de nova Norma Operacional Básica - NOB no 96 -, que impôs modelos e programas assistenciais para atenção básica e delimitou um conjunto de ações simplificadas de saúde (Brasil, 1996), foi considerada, por autores como Bueno e Merhy, uma interferência vertical na autonomia da gestão municipal, ressalvando-se o registro da contribuição dessa norma para avanços importantes na construção do SUS (Bueno \& Merhy, 1997). A forma de financiamento foi alterada com a instituição do Piso da Atenção Básica (PAB), que consiste na transferência de um valor fixo por ano, referente às ações de Atenção Básica - AB, para cada Município em função do número de habitantes. A remuneração vinculada à produção de ações básicas de saúde foi substituída por essa nova forma que segue, em parte, a Lei no 8.080, de 1990, que dispõe sobre o financiamento da saúde com base em critérios demográficos, epidemiológicos e de complexidade da rede. Tal disposição nunca foi plenamente executada, e, desse modo, o recurso financeiro permanece insuficiente para desenvolver ações de atenção integral à saúde.

Embora essa nova forma de repasse represente um avanço em relação ao anterior, que consistia no pagamento por produção de ações, a escassez do recurso financeiro fixo para ações de atenção básica e, em consequência, a necessidade de mais verbas para essa tarefa gerou enfraquecimento da autonomia dos Municípios diante das normas definidas pelo governo federal. Além do piso fixo para atenção básica, o gestor municipal 
pode receber o PAB variável caso desenvolva as modalidades de ações preconizadas pelo Ministério da Saúde. Entre os diversos programas e modalidades de ação formulados na NOB no 96 estão o Programa de Saúde da Família - PSF e o Programa de Agentes Comunitários de Saúde - PACS. Os recursos para tais modalidades não são intercambiáveis, o que complica a prestação de contas do gestor, além de representar o engessamento e o atropelo do planejamento local por tais programas verticais, nos quais o detalhamento normativo emanado do nível central - o Ministério da Saúde (MS) - deve ser cumprido por sistemas municipais de saúde muito heterogêneos, que se estendem em um país de dimensões continentais, para que possam obter recursos federais.

Apenas em 2006 o Ministério da Saúde promoveu mudança na alocação de recursos, através do Pacto de Gestão; essas medidas são positivas, ainda que apenas parcialmente efetivadas: 1 ) redução do número de blocos de financiamento Atenção Básica, Atenção de Média e Alta Complexidade, Vigilância em Saúde, Assistência Farmacêutica e Gestão do SUS; 2) possibilidade de remanejar recursos no interior desses blocos, o que confere maior autonomia aos gestores municipais; 3) a redução das iniquidades macrorregionais, estaduais e regionais deve ser contemplada na metodologia de alocação de recursos e devem ser consideradas, também, as dimensões étnico-racial e social; 4) definição do repasse fundo a fundo ${ }^{1}$ como forma preferencial de transferência de recursos entre os gestores (Brasil, 2006b).

Como já referido, no Brasil, a autonomia dos entes federados torna complexa a relação entre União, Estados e Municípios. A legislação básica do SUS respeita tal autonomia. Não obstante, a modalidade de alocação de recursos definida em portarias e praticada pelos governos federal e estaduais tem constituído, muitas vezes, impedimento para o planejamento, no nível dos Municípios, fundamentado nas necessidades da população local.

O Programa de Saúde da Família (PSF) e os Centros de Atenção Psicossocial (CAPS)

Em síntese, os Municípios se propõem a implantar os vários programas formulados pelo Ministério da Saúde com o objetivo de aumentar suas receitas. No caso do PSF, por exemplo, portarias e manuais produzidos pelo MS detalham como deve ser desenvolvido o trabalho (composição da equipe, carga horária, forma de contratação de pessoal, proporção de famílias a serem atendidas pela equipe). Além disso, o Manual de Organização da Atenção Básica que complementava a NOB no 96 discriminou as ações básicas, mas não incluiu entre elas a atenção à saúde mental e à saúde bucal (Brasil, 1999). Depois de muitas críticas e reiteradas reivindicações de sindicatos de trabalhadores da saúde, do movimento popular e de outros segmentos, tais ações foram incorporadas ao PSF de maneira formal, mas, na prática, isso se deu de forma precária e heterogênea. Em outros termos:

o PSF se configura claramente como um programa vertical do Ministério que concretiza as recomendações do Fundo Monetário Internacional em uma política compensatória na área da assistência à saúde. É também um mecanismo iníquo de financiamento, já que, ao 'premiar' com recursos financeiros - uma das modalidades do PAB variável - os Municípios que se curvam diante de um programa ditado pelo gestor federal do SUS - contribui para o aprofundamento da desigualdade. Como isso se dá? Basta refletir que para os pequenos Municípios é 
muito difícil conseguir contratar médicos, enfermeiros e auxiliares de enfermagem. Então, esses Municípios têm que se contentar com o PACS, cuja remuneração é mais baixa. Praticam, então, uma assistência mais simplificada e de menor custo do que o PSF (Junqueira, 2001, p.19-20)

Atualmente, o PSF foi definido pelo governo federal como estratégia na reorientação do Sistema de Saúde (ESF). Segundo os textos oficiais, são alguns fundamentos dessa estratégia: o território como espaço geográfico, de cultura, de relações sociais e de trabalho local com a população e o estabelecimento de vínculos com produção de acolhimento e responsabilização. Cabe destacar que tais estratégias não são criações originais desse programa, mas sim, práticas constitutivas de modelos assistenciais mais antigos vinculados à medicina comunitária e às ações programáticas da saúde pública.

No que concerne os espaços de trabalho, a contratação de profissionais privilegiada para o PSF e o PACS em detrimento da implantação e da reposição de equipes multiprofissionais nas Unidades Básicas de Saúde (UBS) chamadas tradicionais gerou uma importante redução da contratação de psicólogos e de outros profissionais, com exceção de médicos, enfermeiros e auxiliares. A compensação parcial desse quadro começou a ocorrer com a estruturação de equipes de referência em Saúde Mental para o PSF, ou equipes de matriciamento, e nomeadas pela política oficial como Núcleo de Apoio à Saúde da Família (NASF)², que foi obtida depois de mobilização e reivindicação de usuários e trabalhadores da saúde.

Quando esse programa foi implantado no Brasil, em 1994, seu objetivo era atender minorias sem acesso a serviços de saúde, em regiões brasileiras com escassos recursos de assistência à população; desenvolver ações voltadas para a desmedicalização da sociedade e a humanização dos serviços; colocar a família na agenda das políticas sociais brasileiras (o que reflete, por um lado, os interesses do modelo liberal de responsabilização da família perante o indivíduo que a ela pertence), e, é importante ressaltar, responder à demanda de redução de custos na área de saúde. Embora essa experiência venha possibilitando a problematização do processo saúdedoença-cuidado, a reflexão e a proposição de novos paradigmas de práticas em saúde, esse programa ou estratégia não deixa de estar associado às tendências impostas pelo Fundo Monetário Internacional (FMI) e pelo Banco Mundial pela redução de gastos e investimento em políticas focais em detrimento das universais (Rizzotto, 2000).

Aspectos similares a esses podem ser levantados em relação aos CAPS. O movimento para substituir manicômios por práticas e serviços alternativos aos mesmos e que se estruturou no cerne da luta antimanicomial desembocou, nos últimos anos, em uma política oficial de implementação de Centros de Atenção Psicossocial, como uma das principais estratégias de consolidação da Reforma Psiquiátrica Brasileira.

A política assistencial e de financiamento dos CAPS, no entanto, apresenta um modelo reduzido de assistência à saúde mental ao criar uma política vertical fundamentada em regras de financiamento que privilegiam um tipo de serviço específico. Considerado também, como a ESF, estratégia e centro irradiador de práticas substitutivas, vem sendo implantado por todo o território brasileiro não sendo levados em conta, na 
maioria das vezes, as especificidades locais e o acúmulo teórico-conceitual e técnicoassistencial dos sujeitos desses mesmos territórios.

Os CAPS têm sido assunto frequente nos fóruns de saúde mental, principalmente quando estão em pauta reivindicações ao poder público, cujo teor, muitas vezes, se resume à ampliação do número desses serviços, fundamentadas em portarias governamentais que instituíram e regulamentaram sua estrutura. De acordo com Amarante e Torre (2001), embora tais portarias tenham viabilizado a construção de muitos novos serviços, elas produziram uma homogeneização das experiências originais (os Núcleos de Atenção Psicossocial - NAPS e os próprios CAPS) e, com isso, perdeuse a pluralidade das questões por elas introduzidas.

\section{Quais desafios?}

Aqui podemos nos perguntar sobre o que essa discussão tem a ver com a formação em Psicologia. Como mencionamos anteriormente, a decisão de iniciar o texto pela contextualização e problematização do SUS fundamenta-se na preocupação de não tomarmos projetos e proposições políticas como verdades inquestionáveis ou como modelos a serem apenas aperfeiçoados.

Nesse palco de conflitos e de jogo de interesses, as defesas apaixonadas e a aderência a projetos e políticas como se fossem verdades acabadas têm ocorrido não raramente. Assim, é importante que não deixemos de questionar tais projetos e políticas por mais importantes e relevantes que possam parecer. A ausência de questionamento sobre a validade, sobre os alcances e efeitos de uma proposta, bem como sobre os interesses envolvidos, faz com que se incorra em riscos de desenvolvimento de práticas burocratizadas e em produção de conhecimento estéril.

Essa discussão se justifica, também, porque tem sido frequente a publicação de trabalhos, produzidos por psicólogos ou pesquisadores da área, que fazem reflexões relevantes se circunscritas ao campo da Psicologia, mas que perdem sua força e importância exatamente por terem como pressupostos as políticas, os projetos e os discursos oficiais que quase nunca são questionados.

Desse modo, podemos nos perguntar: além de problematizar a aplicação de técnicas e práticas tradicionais nesse novo cenário de atuação em Psicologia, não caberia também ao psicólogo refletir ou, ao menos, considerar a influência de tais tendências nas práticas derivadas de políticas oficiais? Quais as consequências que as decisões políticas e as definições governamentais trazem para os sujeitos envolvidos nesses projetos e para o próprio projeto?

Indagamos ainda: em que medida, no novo cenário de atuação em Psicologia, é possível desenvolver um trabalho que não se volte apenas para o aprimoramento de novos projetos? Em outros termos, é possível ocupar um lugar que não se restrinja a ser complementar a saberes e fazeres?

Como proposta, sustentamos que uma forma de avançar nessa direção é fazer um movimento mais amplo de inserção nos espaços que se voltam para a construção do conhecimento na área de saúde coletiva e na definição de políticas públicas. Construir um lugar de inserção mais estruturante e menos complementar significa também dar lugar a abertura e a modificação do campo 
de conhecimento da própria Psicologia e da área de atuação dela decorrente.

Para isso, é fundamental que não se perca de vista a preocupação com a filiação histórica das ideias e do confronto de interesses que integram políticas, projetos e saberes, inclusive os das diversas disciplinas no âmbito da produção de conhecimento, incluindo a própria Psicologia. Caso contrário, corre-se o risco de, mais uma vez, reproduzirmos um papel que também essa disciplina já teve no decorrer de sua história, ou seja, o de tomar explicações de caráter eminentemente ideológico, que mascaram a possibilidade de uma relação de conhecimento com a realidade que procuramos desvendar e sobre ela intervir.

Outras preocupações que consideramos de caráter similar merecem ser registradas, e estão relacionadas às configurações históricas da inserção da Psicologia no campo da Saúde, à produção de uma cultura psicológica no Brasil e à despolitização nos processos de formação e inserção profissional dos psicólogos, preocupações que são debatidas por autores interessados na Psicologia e no campo da Saúde Coletiva (Spink \& Matta, 2007; Benevides, 2005; Dimenstein, 2000; Boarini, 2000, são alguns deles).

Enfim, as preocupações apresentadas até aqui foram uma forma de traduzir parte das questões que dizem respeito ao problema da produção do conhecimento em Psicologia no campo da Saúde, o qual está intimamente relacionado à atuação profissional e, em consequência, como já afirmamos inicialmente, à formação em Psicologia para o trabalho na área de saúde.

Pensando sobre a formação na construção do SUS
Podemos perceber, também com fundamento nos trabalhos que refletem sobre a Psicologia no contexto da saúde e da saúde mental (Spink \& Matta, 2007, Benevides, 2005; Dimenstein, 1998, 2001; Boarini \& Borges, 2009), que não é tarefa simples construir o SUS quando se busca radicalizar seus princípios. Não é tarefa fácil traduzir nos serviços, nas práticas do dia-a-dia, as ações que possibilitem o avanço da organização da rede de atenção à saúde, integrada a um processo de territorialização, articulada aos diversos setores do governo e que efetive os princípios de intersetorialidade.

E aqui se apresenta um dos desafios quando nos atemos à temática da formação em Psicologia para o trabalho em saúde, pois essa tarefa exige, entre outras, a definição de políticas que instalem espaços onde possa haver o trânsito entre os âmbitos políticojurídico, socio-cultural, teórico-conceitual e técnico-assistencial, representados por diferentes atores, saberes (popular, científico, teórico-técnico, artístico), instâncias políticas e instituições (universidades, serviços públicos, organizações não governamentais e instituições formadoras, entre outras).

Nesse contexto, as políticas e estratégias para o SUS que se voltam para a formação de futuros e atuais profissionais de saúde estão também em construção, o que implica transcender o sentido estrito de instrução, capacitação e aperfeiçoamento e possibilitar a produção de conhecimento, de mentalidades, de jeitos de estar, de comprometimento com a coisa pública aliada à descoberta e ao exercício do processo de criação.

O fortalecimento de práticas que recuperem o sentido da coisa pública e da valorização dos sujeitos envolvidos nessas práticas exige 
a crítica aos novos modelos de gestão de recursos humanos que fomentam a criação imaginária de uma figura de trabalhadormodelo, pronto a responder e a se adaptar rapidamente às prescrições e às mudanças impostas no novo mundo do trabalho.

\begin{abstract}
Espera-se a constituição de indivíduos a um só tempo conformados, adaptáveis e inovadores, indivíduos teoricamente autônomos, mas, na verdade, heterônomos. As políticas de administração estratégica prometem, hoje em dia, respeitar o sujeito humano, dando-lhe espaço para a manifestação de sua criatividade, para a inovação, mas servem para aliená-lo ainda mais, pois não se trata de certificar-se da consciência profissional do trabalhador, mas de provocar sua adesão passional (Fernandes, 1999, p.44)
\end{abstract}

Não basta, portanto, a apresentação de modos de fazer e de técnicas voltadas para um aprimoramento de estruturas que podem se burocratizar, mas a criação de condições para a construção desses modos de fazer, de pensar, de esquemas conceituais que permitam a implementação criativa de práticas e a ressignificação das políticas orientadoras.

Como já referido, a formação de trabalhadores em saúde é tarefa complexa, pois deve estar voltada para a organização de trabalho coletivo, apoiado em diferentes abordagens. No caso das ações desenvolvidas por profissionais psi e de práticas em saúde mental, outros aspectos aprofundam essa complexidade: o instrumento de trabalho é a própria subjetividade dos trabalhadores e as relações estabelecidas entre eles e também com seus "pacientes", portanto, aspectos intersubjetivos incluem-se como problemática nos projetos de formação. Embora esses aspectos não sejam exclusivos das práticas em saúde mental, nelas deverão ser constantemente problematizados para a efetivação das ações.

Apesar dessas várias características que envolvem a formação e o trabalho em saúde, no que se refere ao ensino acadêmico, ainda predominam, nos cursos universitários, o ideal de autonomia (característico do pensamento liberal) e a ênfase na prática clínica privada como representações valorizadas. Isso reduz o espaço para o aprofundamento de referenciais teóricotécnicos voltados para o fortalecimento de instituições públicas que buscam romper ideias e práticas hegemônicas.

Temos constatado que muitos profissionais saem de seus cursos revelando não se sentirem capazes de desempenhar sua nova função, por não terem apropriado de alguma técnica ou por esta não se adequar à realidade na qual vão atuar, por não terem informações sobre o sistema de saúde e/ou pela falta de conhecimento sobre políticas públicas.

Em pesquisa realizada sobre a experiência de implantação da rede substitutiva em saúde mental no Município de São Paulo, entre os anos 1989 e 1992, constatamos que as expectativas apresentadas pelos trabalhadores que reivindicavam uma política de formação transcenderam a questão da formação em um sentido estrito (capacitação, aprimoramento, treinamento) para demandas que se articulavam à implantação e à organização dos serviços de saúde: a) suprir deficiências da formação universitária e incluir questões relacionadas a uma nova concepção de saúde (novo espaço de formação); b) integrar e organizar os serviços; c) integrar e definir papéis profissionais dentro da equipe; d) sanar problemas de relacionamento da equipe e 
da própria instituição (funcionando como análise institucional) e e) funcionar como lugar de "troca" (intra/inter- equipes e inter/institucional) de conhecimentos, de vivências, de práticas (Scarcelli, 1998).

É possível perceber que os tipos de demanda são de diferentes âmbitos, e as expectativas transcendem o alcance que pode ter uma política de formação, seja esta de caráter acadêmico, sejam aquelas voltadas para o aprimoramento do trabalho para construção do SUS. Tais demandas podem ser compreendidas como um dos aspectos que se somam às dificuldades encontradas no contexto de trabalho: a não percepção de que conhecimentos podem ser produzidos ou ressignificados na prática coletiva.

Nesse sentido, reafirmamos que, concomitantemente à formação para o SUS, faz-se necessário desenvolver, entre outras, estratégias para a produção de conhecimentos que possibilitem a problematização de práticas e políticas implementadas bem como a descoberta de novos caminhos fundamentados por referenciais teórico-técnicos consistentes que sustentem o Sistema, pois o SUS, embora inovador na sua proposta, vem sendo implementado em vários âmbitos de forma burocrática.

Deve-se lembrar, contudo, que "produção de conhecimento" é historicamente associada a institutos de pesquisa e instituições universitárias. Desse modo, as instituições de saúde têm se privado de sistematizar suas experiências e de registrar suas construções, que findam por se perder no tempo e no espaço, principalmente nos momentos de mudança governamental no campo do Poder Executivo.
É importante ressaltar que a sistematização de experiências em forma de registros exige um trabalho de questionamento e de avaliação das práticas, ao mesmo tempo em que permite a inscrição da história dos serviços e, provavelmente, maior envolvimento de trabalhadores como protagonistas da implantação do SUS. Além disso, tais registros podem, também, constituir importante fonte de informação para docentes, pesquisadores e graduandos que não têm os serviços de saúde como algo familiar ou que estudam os mesmos em outra perspectiva.

Antes de finalizar, reafirmamos a defesa de instalação de espaços onde possam transitar diferentes atores e saberes, onde seja possível o cultivo do ato de interrogação e da ressignificação de práticas e políticas públicas. A articulação entre universidade e serviços de saúde, por exemplo, tem propiciado experiências relevantes nesse sentido: os Polos de Educação Permanente e o Programa de Educação pelo Trabalho em Saúde (PET - Saúde), propostos pelo governo federal através dos Ministérios da Saúde e da Educação têm esse potencial; a inserção de estudantes de graduação nas diferentes instâncias do SUS, a partir de estágios que comportam a discussão sistemática entre profissionais da rede de saúde e docentes das universidades e a instalação de fóruns interinstitucionais de pesquisa em serviços de saúde. São espaços que devem ser abertos não só pelo poder público mas também propostos e/ou instalados por universidades, sindicatos, associações, Conselhos de saúde e Conselhos profissionais.

Eis aqui mais um dos desafios para a formação e a produção do conhecimento em Psicologia: construir formas de estar e/ ou incentivar tais espaços que possibilitem a decifração do cotidiano decorrente de definições políticas, sem perder de vista as 
questões referentes às ideias que subjazem aos pressupostos teóricos que nos orientam. Nesse fazer, procurar localizar "os efeitos da determinação dos modos de produção decorrentes da organização social e sua ideologia" (Fernandes, 2005, p. 37).

Essas constituem obrigação ética e necessidade política que exigem, entre outras coisas, o diálogo íntimo a ser construído com outras ciências e disciplinas.

\section{Ianni Regia Scarcelli}

Psicóloga e sanitarista, mestre e doutora em Psicologia Social, professora do Instituto de Psicologia da Universidade de São Paulo, São Paulo - SP - Brasil.

E-mail: iannirs@usp.br

\section{Virgínia Junqueira}

Médica pediatra e sanitarista, mestre e doutora em Ciências, professora da Universidade Federal de São Paulo Campus Baixada Santista, São Paulo - SP - Brasil.

E-mail: virginiaj@uol.com.br

\section{Endereço para envio de correspondência:}

Departamento de Psicologia Social e do Trabalho - Instituto de Psicologia - Universidade de São Paulo Av. Prof. Mello Moraes, 1721 Caixa Postal 66.261 - São Paulo, SP, Brasil CEP 05508-900 


\section{Referências}

ABRASCO, CEBES, ABRES, Rede Unida, AMPASA. (2005). Fórum da Reforma Sanitária Brasileira: Reafirmando Compromissos pela Saúde dos Brasileiros. Manifesto (online). Rio de Janeiro. Recuperado em 04 de junho de 2010. de http://www. abrasco.org.br/publicacoes/arquivos/20060713121020.pdf.

Almeida, C. (2003). As três esferas de governo e a construção do SUS: uma revisão. Revista Saúde em Debate, 27(65), 207-20.

Amarante, P., \& Torre, E. H. G. (2001). A constituição de novas práticas no campo da atenção psicossocial: análise de dois projetos pioneiros na reforma psiquiátrica no Brasil. Revista Saúde em Debate, 58, 26-34.

Benevides, R. B. (2005). A psicologia e o Sistema Único de Saúde: quais interfaces? Psicologia \& Sociedade, 17(2),21-25.

Boarini, M. L. (Org.), (2000). Desafios na atenção à saúde mental. Maringá, PR: Eduem.

Boarini, M. L., \& Borges, R. F. (2009). O psicólogo na atenção básica à saúde. Psicologia: Ciência e Profissão, 29(3), 602613.

Brasil, (1990a). Lei nº 8080 (Lei Orgânica da Saúde). Brasília, DF: Ministério da Saúde.

Brasil. (1990b). Lei no 8142, de 28 de dezembro de 1990. Brasília, DF: Ministério da Saúde.

Brasil. Ministério da Saúde, (1993, 20 de maio). Portaria MS $n^{\circ}$ 545. Brasília, DF: Autor. Recuperado em 06 de junho de 2010 dehttp://siops.datasus.gov.br/Documentacao/ Portaria\%20545_20_05_1993.pdf.

Brasil. Ministério da Saúde, (1996, 5 de novembro). Portaria MS $n^{\circ}$ 2203. Brasília, DF: Autor. Recuperado em 06 de junho de 2010 de http://bvsms.saude.gov.br/bvs/saudelegis/gm/1996/ prt2203_05_11_1996.html.

Brasil. Ministério da Saúde, (1999). Manual para Organização da Atenção Básica. Brasília, DF: Autor. Recuperado em 06 de junho de 2010 de http://www.saude.sp.gov.br/resources/ gestor/acesso_rapido/auditoria/manual_para_organizacao_ atencao_basica.pdf.

Brasil. Ministério da Saúde, (2002, 27 de fevereiro). Portaria GM no 373, de 27 de fevereiro de 2002. Brasília, DF: Autor. Recuperado em 04 de junho de 2010 de http://www.cresspe. org.br/leis/noas.pdf.

Brasil. (2003, 4 de novembro). Resolução n. ${ }^{\circ}$ 333, de 4 de novembro de 2003. Brasília, DF: Imprensa Nacional, 236, seção 1, (p. 57). Recuperado em 04 de junho de 2010 de http://conselho.saude.gov.br/biblioteca/livros/resolucao_333. pdf.

Brasil. Ministério da Saúde. (2006). Política Nacional de Atenção Básica. Brasília, DF: Autor. (Série Pactos pela Saúde, vol. 4).

Bueno, W. S., \& Merhy, E. E. (1997). Os equívocos da NOB no 96: uma proposta em sintonia com os projetos neoliberalizantes? Recuperado em 04 de junho de 2010 de http://www.uff.br/ saudecoletiva/professores/merhy/artigos-14.pdf.

Campos, G. W. S., 1988. A reforma sanitária necessária. In G. Berlinguer; S. F. Teixeira \& G. W. S. Campos Reforma Sanitária: Itália e Brasil. (pp. 179-194), São Paulo: Hucitec.

Campos, G. W. S. (2007). O SUS entre a tradição dos sistemas nacionais e o modo liberal-privado para organizar o cuidado à saúde. Revista Ciência e Saúde Coletiva, 12(Supl.), 1865-1874 
.Carvalho, G. C. M. (2002). O financiamento público federal do Sistema Único de Saúde 1988-2001. Tese de doutorado, Faculdade de Saúde Pública, Universidade de São Paulo, São Paulo.

Cecilio, L. C. O. (2001). As necessidades de saúde como conceito estruturante na luta pela integralidade e equidade na atenção em saúde. In R. Pinheiro, \& R. A. de Mattos, Os sentidos da integralidade na atenção e no cuidado à saúde (pp. 113-126). Rio de Janeiro: IMS/ABRASCO.

Cohn, A. (2008). A reforma sanitária brasileira: a vitória sobre o modelo neoliberal. Social Medicine, 3(2), 82-94.

Constituição Federal. (1988, 5 de outubro). Diário Oficial da União. Brasília, DF.

Coordenação Geral de Apoio à Gestão Descentralizada. Diretrizes Operacionais dos Pactos pela Vida, em Defesa do SUS e de Gestão, (2006). Portaria GM n ${ }^{\circ}$ 699/2006. Brasília, DF: Autor. Recuperado em 04 de junho de 2010 de http:// portal.saude.gov.br/portal/arquivos/pdf/Portaria_699_2006. pdf.

Dejours C. (1986). Por um novo conceito de saúde. Revista Brasileira de Saúde Ocupacional, 54(14), 7-11.

Dimenstein, M. (1998). O psicólogo nas unidades básicas de saúde: desafios para a formação e atuação profissionais. Estudos de Psicologia, 3(1), 53-82.

Dimenstein, M. (2000). A cultura profissional do psicólogo e o ideário individualista: implicações para a prática no campo da assistência pública à saúde. Estudos de Psicologia, 5(1), 95-122.

Dimenstein, M. (2001). O psicólogo e o compromisso social no contexto da saúde coletiva. Psicologia em Estudo, 6(2), 57-63.

Fernandes, M. I. A. (1999). Uma nova ordem: narcisismo expandido e interioridade confiscada. In M. I. A., Fernandes, I. R. Scarcelli, \& E. S. Costa (Org.), Fim de século: ainda manicômios? (pp. 39-46). São Paulo: Instituto de Psicologia da Universidade de São Paulo.

Fernandes, M. I. A. (2005). Negatividade e vínculo: a mestiçagem como ideologia. São Paulo: Casa do Psicólogo.

Heimann, L. S., Cortizo, C. T., Castro, I. E. N., Kayano, J., Rocha, J. L., Nascimento, P. R. do, Boaretto, R., Pessoto, U. C., \& Junqueira, V. (2000). Descentralização do Sistema Único de Saúde: trilhando a autonomia municipal. São Paulo: Sobravime/Hucitec.

Instituto Nacional de Assistência Médica e Previdência Socia - INAMPS. (1991, 7 de janeiro). Resolução INAMPS $n^{\circ}$. 258. Brasília, DF: Autor. Recuperado em 04 de junho de 2010 de http://siops.datasus.gov.br/Documentacao/ Resolu\%C3\%A7\%C3\%A30\%20258_07_01_1991.pdf

Junqueira, V. (2001). Saúde na cidade de São Paulo (1989 a 2000). São Paulo: Instituto Polis/ PUC-SP. (Observatório dos Direitos do Cidadão: acompanhamento e análise das políticas públicas da cidade de São Paulo, 3).

Mendes, E. V. (1996). Uma agenda para a saúde (304 p.). São Paulo: Hucitec.

Merhy, E. E. (2002). Saúde: a cartografia do trabalho vivo em ato. São Paulo: Hucitec.

Nogueira, R. P. (2006). Novas tendências internacionais da força de trabalho no setor público: o Brasil comparado com outros países. (Observatório de Recursos Humanos em Saúde NESP/ CEAM/UnB). Recuperado em 06 de junho de 2010 de http:// www.observarh.org.br/nesp.

Noronha, J. C. de, \& Soares, L. T. (2001). A política de saúde no Brasil nos anos 90. Revista Ciência e Saúde Coletiva, 6(2), $445-450$

Paim, J. S., \& Teixeira, C. F. (2007). Configuração institucional e gestão do Sistema Único de Saúde: problemas e desafios. Revista Ciência e Saúde Coletiva, 12(Supl.), 1819-1829.

Paim, J. S. (2008). A reforma sanitária brasileira e o Sistema Único de Saúde: dialogando com hipóteses concorrentes. Physis Revista de Saúde Coletiva, 18(4), 625-644.

Rizzotto, M. L. F. (2000). O Banco Mundial e as políticas de saúde nos anos 90: um projeto de desmonte do SUS. Tese de doutorado, Faculdade de Ciências Médicas, Universidade Estadual de Campinas, Campinas, SP. Recuperado em 06 de junho de 2010 de http://cutter. unicamp.br/document/?code=vtls000218821.

Santos, N. R. (2008). Política pública de saúde no Brasil: encruzilhada, buscas e escolhas de rumos. Revista Ciência e Saúde Coletiva, 13(S2), 2019-2028.

Santos, N. R. (2007). Desenvolvimento do SUS, rumos estratégicos e estratégias para visualização dos rumos. Revista Ciência e Saúde Coletiva, 12(2), 429-435.

Scarcelli, I. R. (1998). O movimento antimanicomial e a rede substitutiva em saúde mental: a experiência do município de São Paulo (1989-1992). Dissertação de mestrado, Instituto de Psicologia, Universidade de São Paulo, São Paulo.

Scarcelli, I. R. (2002). Entre o hospício e a cidade: exclusão/ inclusão social no campo da saúde mental. Tese de doutorado, Instituto de Psicologia, Universidade de São Paulo, São Paulo.

Scarcelli, I. R., \& Alencar, S. L. S. (2008). Saúde mental e saúde coletiva: intersetorialidade e participação em debate. Cadernos Brasileiros de Saúde Mental, 1(1), [CD-ROM].

Spink, M. J., \& Matta, G. C. (2007). A prática profissional psi na saúde pública: configurações históricas e desafios contemporâneos. In M. J. Spink (Org.), A psicologia em diálogo com o SUS: prática profissional e produção acadêmica. São Paulo: Casa do Psicólogo.

Spink, M. J. (Org.), (2007). A psicologia em diálogo com o SUS: prática profissional e produção acadêmica. São Paulo: Casa do Psicólogo. 